\title{
Influence of coated olivine on the conversion of intermediate products from decomposition of biomass tars during gasification
}

\author{
Matthias Kuba $^{1,2} \cdot$ Friedrich Kirnbauer $^{1} \cdot$ Hermann Hofbauer $^{2}$
}

Received: 19 January 2016 /Revised: 13 March 2016/Accepted: 15 March 2016

(C) The Author(s) 2016. This article is published with open access at Springerlink.com

\begin{abstract}
Steam gasification of solid biomass in dual fluidized bed systems is a suitable technology for the production of chemicals, fuels for transportation, electricity, and district heating. Interaction between biomass ash and bed material leads to the development of Ca-rich bed particle layers. Furthermore, incomplete decomposition of biomass leads to the formation of tar components; among these are stable intermediate products such as $1 \mathrm{H}$-indene and stable gaseous hydrocarbons such as methane. In this work, the influence of bed particle layers on the conversion of intermediate products such as $1 \mathrm{H}$-indene and methane via steam reforming was investigated by conducting experiments in a lab-scale test rig. Satisfying conversion of $1 \mathrm{H}$-indene into gaseous molecules (e.g., $\mathrm{CO}, \mathrm{CO}_{2}, \mathrm{H}_{2}$ ) was achieved with used, layered olivine, whereas fresh olivine showed significantly poorer performance. Since steam reforming was connected to the watergas-shift reaction for the tested hydrocarbons, investigations regarding carbon monoxide conversion in the presence of steam were conducted as well. Furthermore, a comparison of the influence of fresh and used bed material concerning the conversion of methane is presented, showing that methane is not affected by the bed material, independent of the presence of particle layers.
\end{abstract}

Keywords Biomass gasification - Bed material coating · Catalytic conversion $\cdot$ Steam reforming $\cdot 1 \mathrm{H}$-indene $\cdot$ Methane

Matthias Kuba

matthias.kuba@bioenergy2020.eu

1 Bioenergy 2020+ GmbH, Wienerstraße 49, A-7540 Güssing, Austria

2 Institute of Chemical Engineering, Vienna University of Technology, Getreidemarkt 9/166, 1060 Vienna, Austria

\section{Introduction}

The utilization of renewable energy carriers to substitute for fossil fuels plays an important role in meeting the worldwide aim to reduce greenhouse gas emissions, but requires innovative and efficient technologies. Climate change is partially a consequence of the combustion of fossil resources, and rising awareness of global warming has increased the necessity of developing "green technologies." Biomass is the only renewable carbon source usable as a $\mathrm{CO}_{2}$-neutral feedstock for pyrolysis, combustion, or gasification [1].

A dual fluid bed (DFB) gasification system was developed by the Vienna University of Technology, where the solid feedstock is transformed into a gaseous secondary energy carrier. Endothermic gasification and exothermic combustion are conducted in two separate reactors with the bed material circulating between those two reactors. This bed material acts both as a heat carrier and catalyst, as described in more detail in Sect. 2.1. While air is used for the fast fluidized bed in the combustion reactor, the gasifier is fluidized with steam. As a consequence, the product gas from this specific gasification is practically free of nitrogen and can be further used as a valuable synthesis gas for the production of a variety of different end products [2]. Examples of such products are bio-methane [3, 4], Fischer-Tropsch bio-diesel [5, 6], pure hydrogen [7-9], or mixed alcohols [10]. Therefore, this technology is also referred to as polygeneration. This flexibility of the process allows it to quickly react to changes in the energy market.

This technology has been successfully used in industrialscale power plants since 2001. In Güssing, Austria, the first power plant started operation with a fuel power of $8 \mathrm{MW}_{\text {th }}$. Further, power plants using the same DFB setup are under operation in Oberwart, Austria (fuel power of $8.5 \mathrm{MW}_{\text {th }}$ ), Senden, close to Ulm, Germany (fuel power of $16 \mathrm{MW}_{\text {th }}$ ), and Gothenburg, Sweden (fuel power of $30 \mathrm{MW}_{\text {th }}$ ). A new 
generation of DFB gasification is currently being developed at the Vienna University of Technology. A new design of the gasification unit increases the contact between the catalytically active bed material and gas released from the biomass feedstock [11-13].

Gas released from biomass feedstock contains heavier hydrocarbons, which are also referred to as tars. These tars are primarily produced in the pyrolysis stage due to breakage of the three main constituents of biomass: cellulose, hemicellulose, and lignin. As a result, primary tars, such as phenol and creosol, are formed. At temperatures above $500{ }^{\circ} \mathrm{C}$, these primary tars recombine into heavier molecules, referred to as secondary tars. A further temperature increase leads to the destruction of primary and secondary tars, resulting in the production of tertiary tars, such as naphthalene or pyrene. These are highly undesirable by-products when they condense in downstream equipment [14]. Therefore, reducing these compounds is necessary to obtain a valuable product gas.

The mechanism behind tar decomposition has been investigated in the past [15-17]. Figure 1 shows the decomposition mechanism of naphthalene [15]. As it can be seen, stable intermediate products, such as $1 \mathrm{H}$-indene, toluene, and benzene, are formed, which have to be further converted to produce small gaseous molecules. The reactivity of $1 \mathrm{H}$-indene has not been addressed in the literature so far. A comparison of one-ring and poly-ring hydrocarbons has been published [18]. Furthermore, the conversion of toluene has been investigated [19-21]. The typical gaseous products that form during biomass steam gasification are carbon monoxide (CO), hydrogen $\left(\mathrm{H}_{2}\right)$, methane $\left(\mathrm{CH}_{4}\right)$, and carbon dioxide $\left(\mathrm{CO}_{2}\right)$. In lesser amounts, the product gas also contains larger molecules, such as ethene $\left(\mathrm{C}_{2} \mathrm{H}_{4}\right)$. The molecules $\mathrm{CO}, \mathrm{H}_{2}$, and $\mathrm{CO}_{2}$ are the result of steam reforming reactions and the water-gas shift reaction, which is explained in more depth in Sect. 2.3. The occurrence of $\mathrm{CH}_{4}$ is most likely a consequence of both direct release from solid biomass feedstock [22] and the decomposition of heavier hydrocarbons [23].

Tar measurements from industrial-scale gasification power plants in Oberwart, conducted in earlier projects, and in Senden have shown notable differences regarding the distribution of tar components. The results from the power plant in Senden show significantly higher values of $1 \mathrm{H}$-indene. A scrubber unit operated with rapeseed methyl ester (RME) is used for gas cleaning. Since the scrubber has a significantly lower separation efficiency for intermediate products, such as $1 \mathrm{H}$-indene, than for heavier poly-cyclic hydrocarbons, as previously described [24], they might cause operational problems in downstream equipment due to condensation and the buildup of deposits. As a result, intermediate products such as $1 \mathrm{H}-$ indene from tar decomposition are highly undesirable.

As explained above, the conversion of tars into smaller gaseous molecules can be achieved through steam reforming reactions, since steam is used as the fluidization medium in the gasifier. These reactions take place in the presence of a catalyst, which is the bed material, the ash, and additives in the case of the DFB process. The behavior of this inorganic matter in DFB gasification has been described by Kirnbauer et al. [25].

Through interactions between biomass ash and bed materials in the fluidized bed, the formation of calcium-rich layers on bed particles can occur during combustion [26] as well as for olivine particles in gasification [27]. Interactions between ash components and the bed material have different consequences. The formation of layers on bed particles can result in agglomeration, slagging, and deposit buildup [25, 28-32]. However, calcium-rich layers have shown a significant increase of the catalytic activity of bed particles [33-36] and are therefore highly desirable for gasification processes. Consequently, layer formation on bed particles has both positive and negative impacts on the gasification process.

In this work, lab-scale experiments were conducted to investigate the influence of calcium-rich bed particle coatings on the conversion of the intermediate tar decomposition products $1 \mathrm{H}$-indene and methane. Thus, the catalytic activity of fresh and used, layered particles were compared to each other. Since the water-gas-shift reaction is linked to steam reforming of the investigated compounds and occurred as follow-up reaction, carbon conversion in the presence of steam was also addressed. In addition, experiments concerning the conversion of methane were performed to understand how the product gas composition can be influenced in situ with layered bed material. Understanding the catalytic activity of layered bed material regarding intermediates from tar decomposition offers the possibility of identifying indicator components for incomplete transformation, which can be caused by, e.g., problems with fuel mixing. Components which should be transformed in the presence of the bed material, but are still present in the product gas, are such indicator components.

These tests are follow-up experiments from previous work, where the influence of such coatings was investigated for steam reforming of toluene and $\mathrm{C}_{2} \mathrm{H}_{4}$ [34]. Both publications together give a comprehensive overview of the influence of calcium-rich bed particle layers on the reduction of tars and the product gas composition.

\section{Materials and methods}

\subsection{Description of the dual fluid bed steam gasification of biomass}

The DFB power plant in Senden has a fuel power of $16 \mathrm{MW}_{\text {th }}$ and uses logging residues as feedstock. A detailed description of the feedstock was provided in a previous work [30]. 


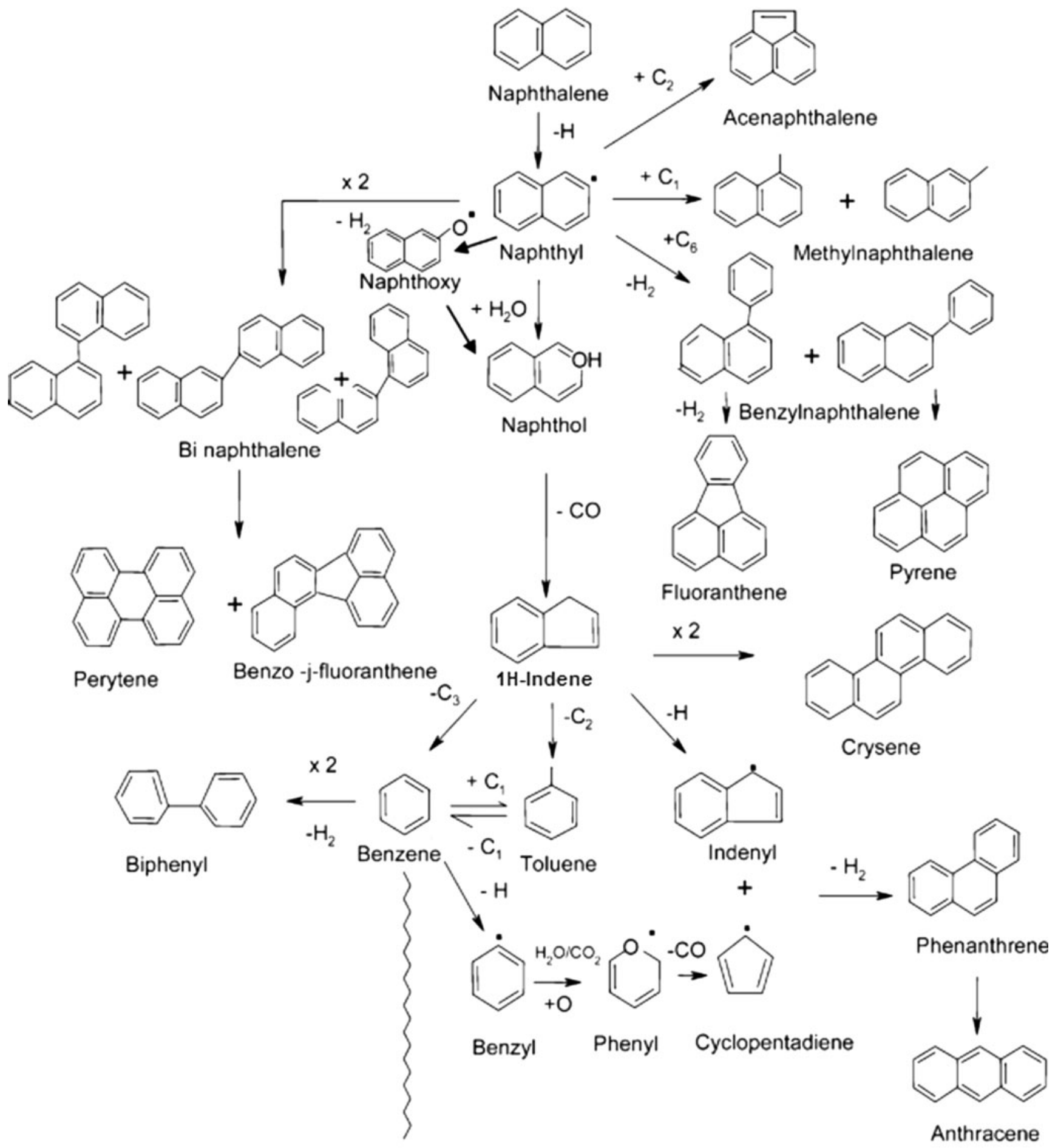

\section{Permanent gases}

(e.g. $\mathrm{CO}, \mathrm{CO}_{2}, \mathrm{CH}_{4}, \mathrm{H}_{2}$ )

Fig. 1 Decomposition mechanism of naphthalene as proposed by Devi et al. [15] (adapted)

Figure 2 shows the flow sheet of the DFB gasification process as it occurs in the power plant in Senden, Germany. A screw conveyer system transports solid feedstock into the bubbling fluidized bed of the gasifier. Therefore, volatile matter released from the biomass comes immediately into contact with the catalytically 


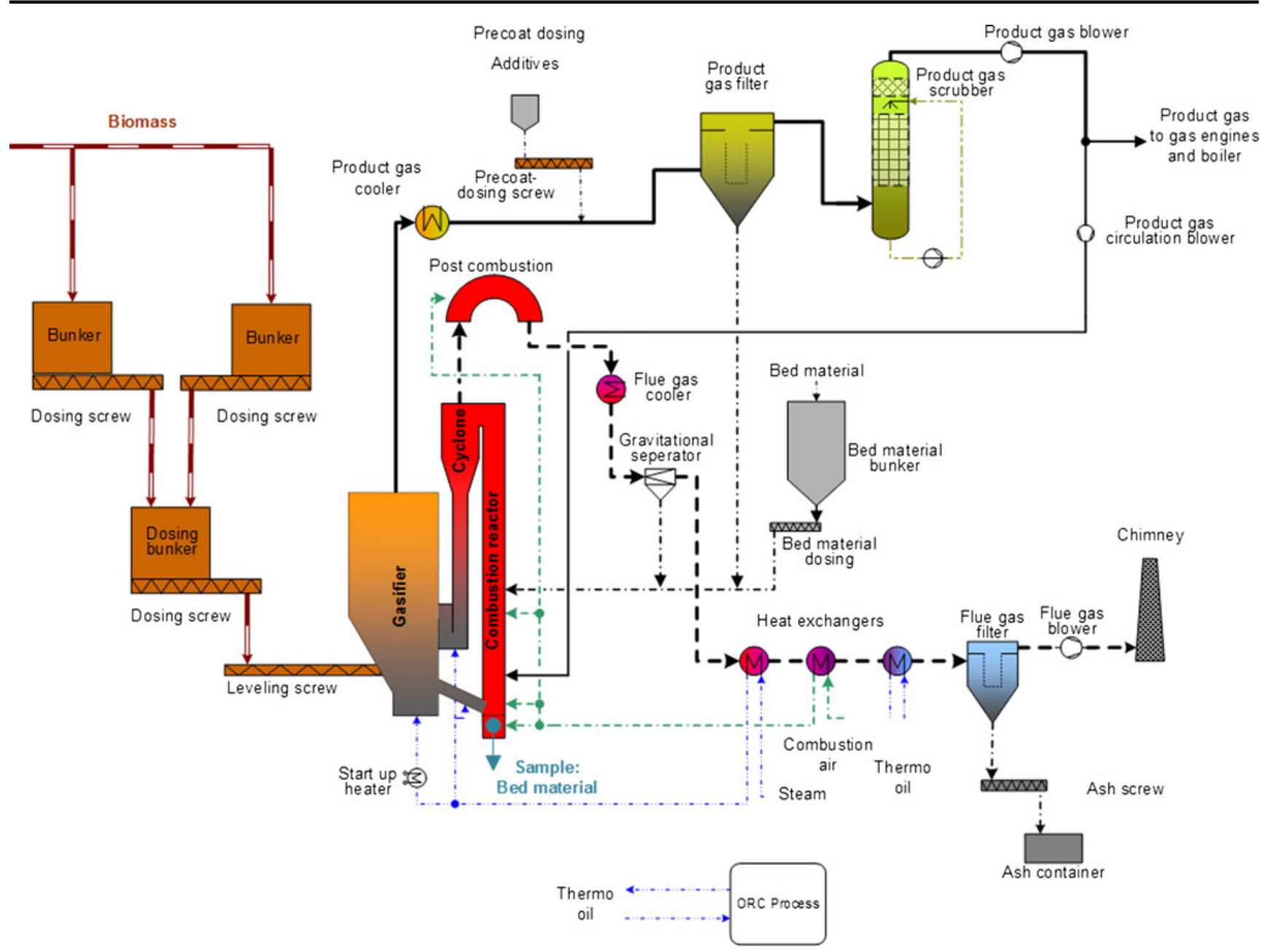

Fig. 2 Flow sheet of the DFB gasification plant in Senden

active bed material. Olivine is currently used as the bed material in all industrial power plants.

Gasification is conducted at a bed temperature of around $850{ }^{\circ} \mathrm{C}$ using steam as the gasifying agent. Calcium oxide is brought into the gasifier as an additive to further increase the catalytic activity toward tar reduction. Part of the biomass char enters into the combustion reactor via a chute where air is used as the fluidizing agent and combustion is performed at temperatures up to $930{ }^{\circ} \mathrm{C}$. After the combustion reactor, bed particles are separated from the flue gas stream in a cyclone and transported back to the gasifier, thus providing the heat for gasification. Flue gas passes through a post-combustion chamber to ensure complete oxidation of the combustible compounds before it is cooled down in heat exchangers. Fine ash is separated from the gas stream in a flue gas filter and is removed from the system.

As a result of this separation of gasification and combustion, the valuable product gas is not mixed with the flue gas. The product gas is cooled down in a series of heat exchangers and cleaned after leaving the gasifier. Particles are separated from the gas stream in the product gas filter, and tars and water are removed in the product gas scrubber. RME is used as the solvent for tars in the scrubber. After the scrubber unit, the clean product gas is then available for further usage. In the power plant in Senden, the product gas is used as fuel for two gas engines, resulting in the generation of electricity and district heating.

Fresh olivine samples were collected on site before start-up of the power plant. Used olivine samples were gathered during steady state operation from the bottom of the combustion reactor, as shown in Fig. 2. Samples were collected from four different days of operation.

\subsection{Bed materials}

To investigate the catalytic activity of bed particle coatings regarding the conversion of the compounds, fresh and used olivine samples were compared to each other. Fresh olivine was pretreated by calcination at $1200{ }^{\circ} \mathrm{C}$. The detailed procedure of such a pretreatment has been previously described [ 37 , 38]. The consequences of pretreatment itself regarding the catalytic activity of the material were not part of this work 
and will therefore not be discussed further. An image from analysis in a scanning electron microscope (SEM) from a used olivine particle with a Ca-rich layer is shown in Fig. 3. As it can be seen, the surface is covered by the layer. Thus, the particle layer can be understood as catalytic coating on the olivine particle, which has the role of a support material. Detailed information on the interaction between olivine and biomass leading to such a layer has been presented by Kirnbauer et al. [27, 39].

Both olivine samples were compared to two benchmark materials. First, feldspar was used as a non-active inert material which does not influence the reactions. Second, calcium oxide $(\mathrm{CaO})$ was used as natural material with high catalytic activity. Since the particle layers on olivine are $\mathrm{Ca}$-rich, pure $\mathrm{CaO}$ serves as a benchmark for the highest activity due to active sites in the Ca-rich layer.

Bed material samples were sieved into a fraction of 400 $800 \mu \mathrm{m}$ to obtain comparable results. This was realized by first sieving the materials into three separate fractions, namely, 400-500, 500-630, and 630-800 $\mu \mathrm{m}$. Then, $3.33 \mathrm{~g}$ was taken from each fraction and mixed together, resulting in samples with similar particle diameters. These samples were used for further investigations.

\subsection{Test reactions}

Experiments were conducted to determine the catalytic activity of the bed materials toward the conversion of hydrocarbons. Three reactions, which are relevant in gasification, will be discussed in detail.

The intermediate tar decomposition product $1 \mathrm{H}$-indene was examined in detail. In-bed transformation of $1 \mathrm{H}-$ indene was investigated in lab-scale tests using the bed materials described above. On that account, steam reforming of $1 \mathrm{H}$-indene was investigated, based on the following reaction formula:

$$
\mathrm{C}_{9} \mathrm{H}_{8}+9 \mathrm{H}_{2} \mathrm{O} \leftrightarrow 9 \mathrm{CO}+13 \mathrm{H}_{2}
$$

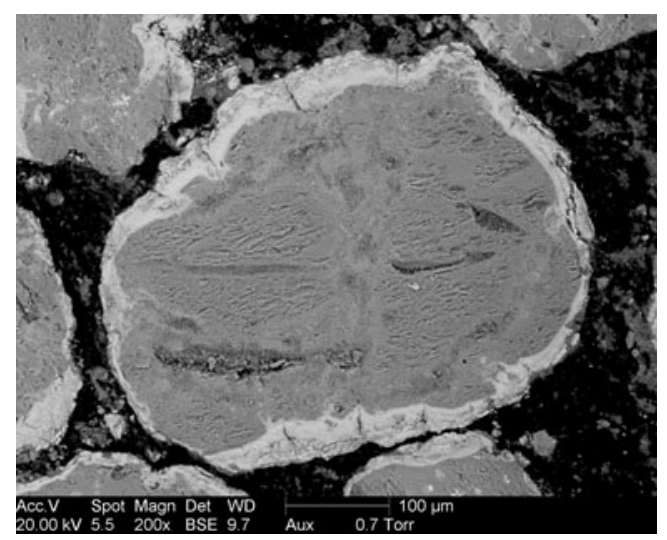

Fig. 3 SEM image of a used, layered, olivine particle
However, excess steam was used, resulting in input streams of $8.2 \mathrm{~cm}^{3} \mathrm{~h}^{-1}$ of $1 \mathrm{H}$-indene and a corresponding steam flow of $22.7 \mathrm{gh}^{-1}$. All gas volumes of the input streams were measured at standard conditions of $101.3 \mathrm{kPa}$ and $273.15 \mathrm{~K}$. The desired carrier flow stream for the evaporators was nitrogen $\left(\mathrm{N}_{2}\right)$ with volumetric flow rates of $1.5 \times 10^{-3} \mathrm{~m}^{3} \mathrm{~h}^{-1}$ for the water evaporator and $1.0 \times 10^{-3} \mathrm{~m}^{3} \mathrm{~h}^{-1}$ for the $1 \mathrm{H}$-indene evaporator, respectively. Experiments with $1 \mathrm{H}$-indene were performed for a temperature of $800{ }^{\circ} \mathrm{C}$. This temperature was chosen, based on findings from previous work conducted by Kirnbauer et al. [40], where $800{ }^{\circ} \mathrm{C}$ was identified as the optimal operation temperature regarding the reduction of tars.

Since steam reforming of investigated hydrocarbons in this and previous work [34] was coupled with the water-gas-shift reaction, the influence of particle layers solely regarding this follow-up reaction was also addressed in this work to give a comprehensive overview:

$\mathrm{CO}+\mathrm{H}_{2} \mathrm{O} \leftrightarrow \mathrm{CO}_{2}+\mathrm{H}_{2}$

For these tests, the chosen volumetric flow rate of $\mathrm{CO}$ was $1.5 \times 10^{-2} \mathrm{~m}^{3} \mathrm{~h}^{-1}$ and the corresponding mass flow rate of $\mathrm{H}_{2} \mathrm{O}$ was $12.05 \mathrm{gh}^{-1}$. The carrier gas for the steam generator was $\mathrm{N}_{2}$, with the same volumetric flow rate as that of $\mathrm{CO}$. Thus, an input concentration of $\mathrm{CO}$ of $50 \%$ based on the dry gas volume $\left(\mathrm{CO}\right.$ and $\left.\mathrm{N}_{2}\right)$ into the reactor was supplied. The water-gas-shift reaction was also addressed in previous work [34]; however, since it occurs as follow-up reaction in steam reforming of hydrocarbons, results are also shown in the present work to address the complete reaction path.

Furthermore, tests were conducted to investigate the transformation of $\mathrm{CH}_{4}$ by steam reforming with fresh and used, layered olivine. As a result, the influence of the increased catalytic activity of Ca-rich layers on transformation of $\mathrm{CH}_{4}$, and therefore on the product gas composition was examined.

$$
\mathrm{CH}_{4}+\mathrm{H}_{2} \mathrm{O} \leftrightarrow \mathrm{CO}+3 \mathrm{H}_{2}
$$

For the experiments, a volumetric flow rate of $\mathrm{CH}_{4}$ was $1.1 \times 10^{-2} \mathrm{~m}^{3} \mathrm{~h}^{-1}$ and a corresponding mass flow rate of $\mathrm{H}_{2} \mathrm{O}$ of $17 \mathrm{gh}^{-1}$ were applied. The carrier gas flow stream for the steam generator was $\mathrm{N}_{2}$ with the same volumetric flow rate as that of $\mathrm{CO}$. Therefore, the input flow rates supplied an input concentration of $\mathrm{CH}_{4}$ of $50 \%$ based on dry gas volume $\left(\mathrm{CH}_{4}\right.$ and $\left.\mathrm{N}_{2}\right)$ into the reactor.

\subsection{Lab-scale test rig for catalytic measurements}

Figure 4 shows a flow chart of the employed test rig. The model tar component 1H-indene (Fig. 4(1)) was introduced in liquid state via a syringe pump. The liquid was pushed into an evaporator where complete transformation of $1 \mathrm{H}$-indene into the gaseous state was achieved. The evaporator was operated at a temperature of $220^{\circ} \mathrm{C}$. A carrier gas stream was 


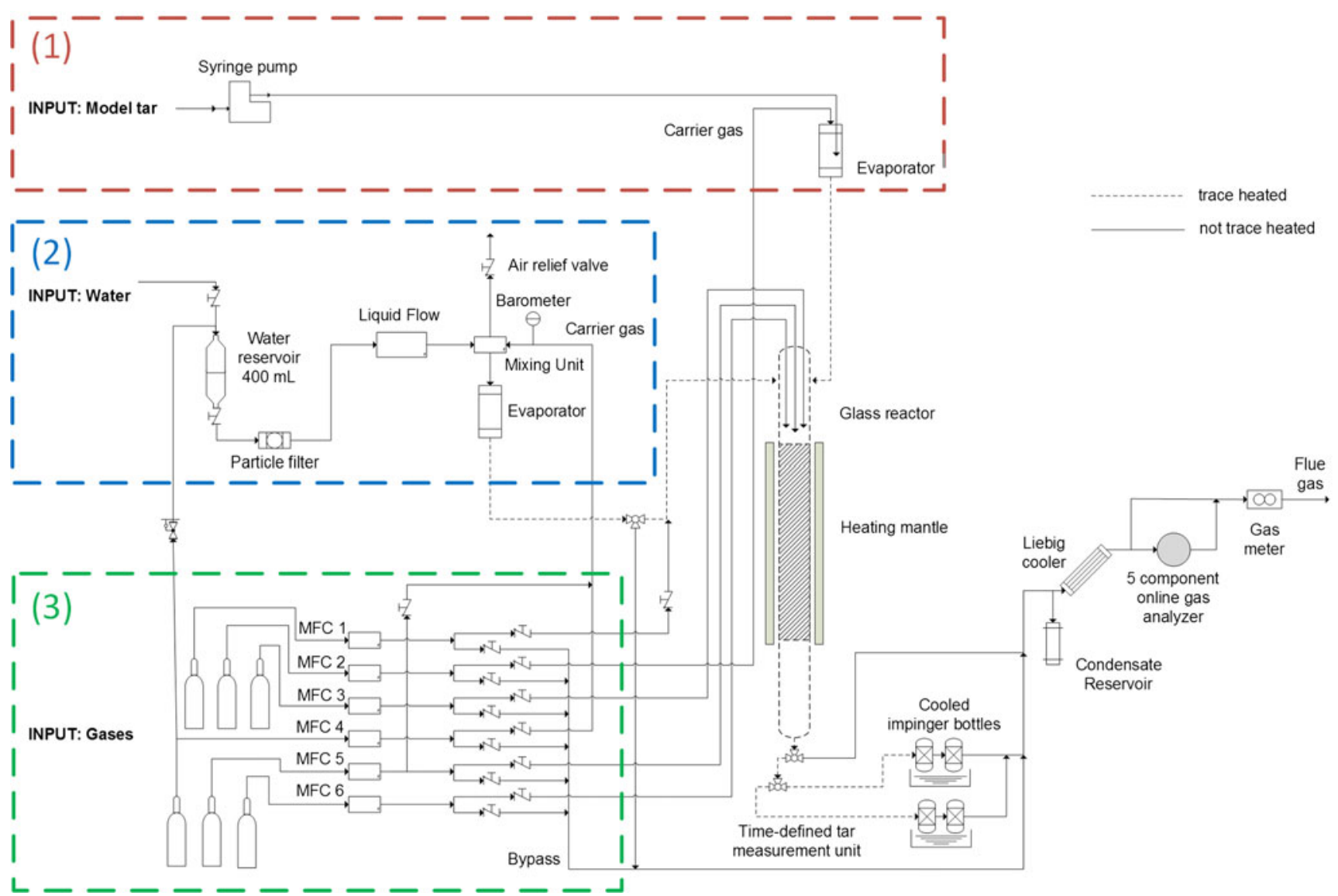

Fig. 4 Flow sheet of the lab-scale test rig for catalytic measurements

brought into the evaporator to drag the evaporated tar compound to the reactor zone. Nitrogen was used as the carrier gas for all experiments, since it is inert and therefore does not interfere with the reactions to a noteworthy extent but merely dilutes the produced gas. Demineralized water (Fig. 4(2)) was transported separately to the reactor zone. Pressurized $\mathrm{N}_{2}$ pushed the water from a reservoir through a liquid mass flow controller. Then, it was brought to a controlled evaporator mixer (CEM) from Bronkhorst, where it was mixed with a carrier gas. The evaporator was operated at a temperature of $135{ }^{\circ} \mathrm{C}$. Nitrogen was used as the carrier gas, analogous to the model tar carrier gas stream. A mixture of water and the carrier gas was either led directly to the reactor zone or switched to a bypass. All pipes leading to the reactor were trace heated to $200{ }^{\circ} \mathrm{C}$ to avoid premature condensation.

It is possible to introduce up to six different gases (Fig. 4 (3)) into the reactor simultaneously. The gas streams were introduced via mass flow controllers (MFCs). All gas streams could be separately switched to bypass or led to the reactor zone. Bypass mode was used to calibrate the measurement equipment and ensure its functionality. Calibration was conducted by the certified Test Laboratory for Combustion Systems of the Vienna University of Technology.
Figure 5 shows a more detailed scheme of the reactor part. A quartz glass tube with an inner diameter of $1.0 \mathrm{~cm}$ and an outer diameter of $1.2 \mathrm{~cm}$ was used as the reactor. Bed material particles of around $10 \mathrm{~g}$ were inserted as a fixed bed, resulting in a bed height of about $7.4 \mathrm{~cm}$. Quartz wool inside the quartz

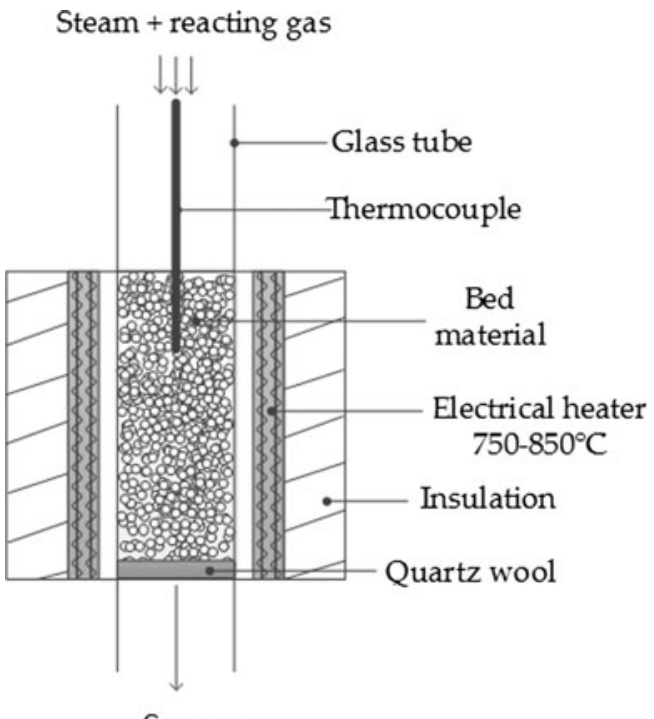

Syngas

Fig. 5 Scheme of the reactor part 
glass reactor held the particles in position. Gas streamed downward from top to bottom during the experiments. A heating furnace was placed around the quartz glass reactor, and a thermocouple continuously measured and controlled the bed temperature inside. A second thermocouple was placed outside the quartz glass reactor which continuously measured the wall temperature of the reactor outside of the fixed bed. This second thermocouple was used to constantly check the functionality of the thermocouple inside the reactor. When an increasing offset of the temperature measurement inside the reactor was observed, the experiment was stopped and the thermocouple was cleaned before starting again. Temperatures between 750 and $850{ }^{\circ} \mathrm{C}$ were investigated in this work. The temperature was continuously controlled, and therefore, constant temperature levels were ensured throughout the experiments. Quartz wool was installed as insulation outside of the reactor to reduce heat losses during operation.

Gas leaving the reactor was led through two impinger bottles, which were connected in series and were placed inside a cryostat. The cryostat was kept at a temperature of $0.1^{\circ} \mathrm{C}$. The exact procedure of tar sampling and measurement is explained in more depth in Sect. 2.5.

After the cryostat, a Liebig cooler was installed as a security measure to protect the measurement equipment in case of failure of the cryostat. The cooling medium of the Liebig cooler was also kept at a temperature of $0.1{ }^{\circ} \mathrm{C}$. Condensed liquid phases were collected in a reservoir. The gas stream was then led to the measurement station, which consisted of a fivecomponent Rosemount NGA 2000 online gas analyzer and an automatic data recording unit. Measurement of $\mathrm{CO}, \mathrm{CO}_{2}$, $\mathrm{CH}_{4}, \mathrm{H}_{2}$, and $\mathrm{O}_{2}$ was carried out by the online analyzer, and data were recorded every $10 \mathrm{~s}$. Before the off-gas was finally released through a vent, the volume flow was measured by a gas meter.

Experiments were conducted until a constant composition of the produced gas was observed. Afterwards, steady state operation was carried out for $30 \mathrm{~min}$. Values for the evaluation of the catalytic activity were taken from steady state operation. Each experiment was repeated three times to ensure reproducibility of the results.

\subsection{Tar sampling and measurement}

Tar sampling from the lab-scale test rig was inspired by the Tar Sampling Guidelines [41], but was adapted for the apparatus. Figure 6 shows the setup as it was installed in the test rig. Gas was led through two consecutive impinger bottles in bypass mode at all times. The impinger bottles were filled with toluene as the solvent instead of a mixture of dry ice with isopropanol as suggested in the guidelines, since measuring $1 \mathrm{H}$-indene was the primary goal. Time-defined tar sampling was performed by switching to two separate bottles, when a
Product gas from quartz glass reactor

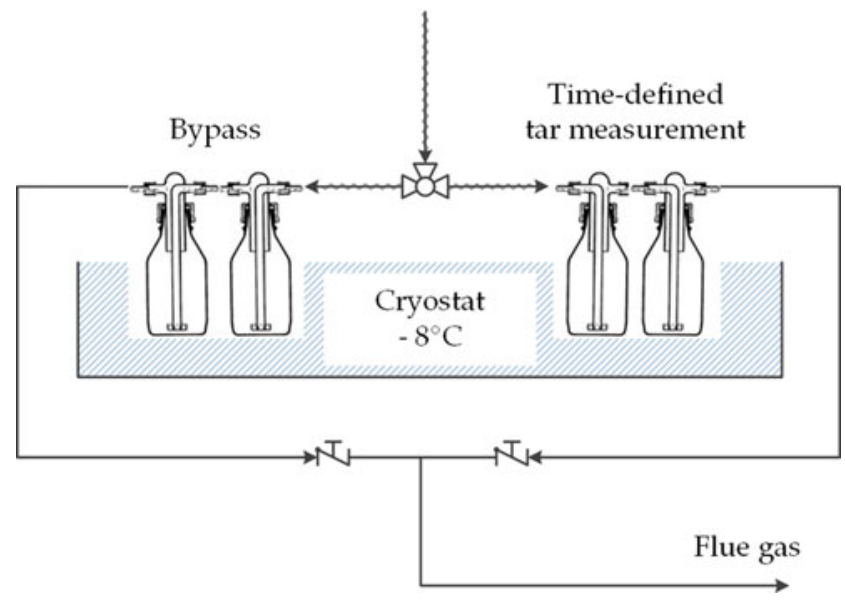

Fig. 6 Setup of the tar measurement unit in the lab-scale test rig

constant composition was measured for the produced gas. Time-defined tar sampling was conducted for $30 \mathrm{~min}$. Pipes connecting the reactor outlet and the inlet to the bottles were constantly trace heated to a temperature of $200{ }^{\circ} \mathrm{C}$ to avoid losses through condensation.

Measurement of collected tar samples was performed by the certified Test Laboratory for Combustion Systems at the Vienna University of Technology using a GC/MS to identify single tar components.

\section{Results}

\subsection{Catalytic activity of bed material particles}

The influence of catalytic activity regarding the transformation of $1 \mathrm{H}$-indene is presented. Conversion of $1 \mathrm{H}$-indene at $800{ }^{\circ} \mathrm{C}$ in the presence of different bed materials is shown in Fig. 7. Feldspar did not show noteworthy catalytic activity.

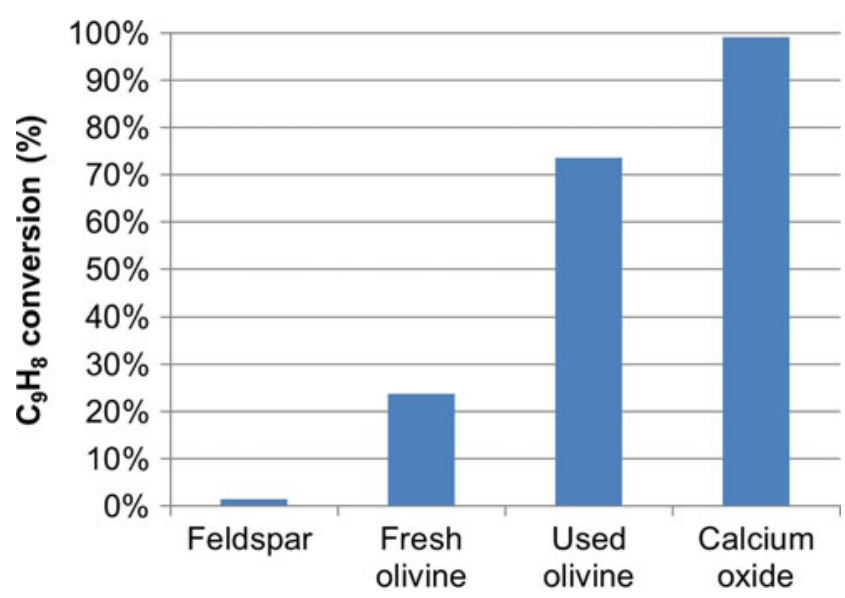

Fig. 7 Conversion of $1 \mathrm{H}$-indene during steam reforming at $800{ }^{\circ} \mathrm{C}$ 
Fresh olivine reached more than $20 \%$ conversion; however, this was significantly less than used, layered olivine which converted more than $70 \%$ of $1 \mathrm{H}$-indene. Almost complete conversion could be achieved when using the benchmark material $\mathrm{CaO}$.

Table 1 shows the dry gas composition $\left(\mathrm{CO}, \mathrm{CO}_{2}, \mathrm{CH}_{4}\right.$, $\mathrm{H}_{2}$ ) of steam reforming of $1 \mathrm{H}$-indene performed with the different bed materials. Moreover, the carrier gas $\mathrm{N}_{2}$ is not included in the composition. The $\mathrm{H}_{2}$ composition rose with increasing catalytic activity. Materials with lower catalytic activity, such as feldspar and fresh olivine, showed significantly higher selectivity toward $\mathrm{CO}$ compared to $\mathrm{CO}_{2}$. In comparison, for used olivine and $\mathrm{CaO}$, which possess higher catalytic activity, increased amounts of $\mathrm{CO}_{2}$ compared to $\mathrm{CO}$ were observed. The amounts of $\mathrm{CH}_{4}$ were close to the detection limit for all investigated samples.

Tar measurements during the experiments with the labscale test rig showed the presence of chrysene, a heavier poly-cyclic hydrocarbon. This polymerization, as described in Fig. 1, was observed during all test runs. The results are presented in Table 2. Increasing catalytic activity led to decreasing polymerization of $1 \mathrm{H}$-indene. The amounts of chrysene were close to the detection limit when $\mathrm{CaO}$ was used as the catalyst.

Part of the $\mathrm{CO}$ produced during steam reforming reacts further with steam to form $\mathrm{CO}_{2}$, and $\mathrm{H}_{2}$. This water-gas-shift reaction occurred as a follow-up reaction to the investigated steam reforming reaction. Figure 8 shows the conversion of $\mathrm{CO}$ from separate experiments (see Sect. 2.3) at temperatures from 750 to $850^{\circ} \mathrm{C}$ using feldspar, fresh, and used olivine as well as $\mathrm{CaO}$. In those experiments, the water-gas-shift reaction was investigated isolated from any other reactions. Analogous to the steam reforming of $1 \mathrm{H}$-indene, feldspar did not show any catalytic activity. Used olivine achieved significantly higher conversion of $\mathrm{CO}$ than fresh olivine. The equilibrium of the reaction was almost reached when the benchmark material $\mathrm{CaO}$ was used as the catalyst.

Steam reforming of methane was conducted using both fresh and used olivine according to the description in Sect. 2.3. In addition, the temperature dependency was investigated by conducting the experiments at 750,800 , and $850^{\circ} \mathrm{C}$. The conversion of methane is displayed in Fig. 9. As it can be seen, only minimal conversion of methane was achieved with both

Table 1 Dry gas composition of $1 \mathrm{H}$-indene steam reforming at $800^{\circ} \mathrm{C}$

\begin{tabular}{ccccc}
\hline & $\mathbf{C O}$ & $\mathbf{C O}_{\mathbf{2}}$ & $\mathbf{C H}_{\mathbf{4}}$ & $\mathbf{H}_{\mathbf{2}}$ \\
\hline \multirow{5}{*}{ Average } & gas & composition $(\%)$ & \\
Feldspar & 22.0 & 5.7 & 0.4 & 71.9 \\
Fresh olivine & 15.8 & 9.6 & 0.2 & 74.4 \\
Used olivine & 6.0 & 18.5 & 0.5 & 75.0 \\
$\mathrm{CaO}$ & 3.1 & 18.8 & 0.2 & 77.9 \\
\hline
\end{tabular}

Table 2 Polymerization of $1 \mathrm{H}$-indene to chrysene at $800{ }^{\circ} \mathrm{C}$

\begin{tabular}{lccc}
$\begin{array}{l}\text { Feldspar } \\
\text { (\%) of total input }\end{array}$ & Fresh olivine & Used olivine & $\mathrm{CaO}$ \\
\hline $\begin{array}{ccc}1 \\
+-0.3\end{array}$ & $+/-0.4$ & 1.1 & 0.2 \\
$+/-0.2$ & $+/-0.1$ \\
\hline
\end{tabular}

materials. Fresh olivine did not show significant catalytic activity, and the coating of the used olivine did not increase it either. Increasing the temperature from 750 up to $850{ }^{\circ} \mathrm{C}$ promoted the conversion of $\mathrm{CH}_{4}$ by less than $1 \%$ and was still less than $2 \%$ for both materials.

\section{Discussion}

In tar measurements from the DFB gasification of woody biomass, naphthalene is one of the major components [33]. Therefore, in this work, decomposition is discussed using naphthalene as a model compound for biomass tars. The decomposition mechanism of naphthalene, as described by Devi et al. [15] and presented in Fig. 1, shows that $1 \mathrm{H}$-indene is a stable intermediate compound. Therefore, the detection of increased amounts of $1 \mathrm{H}$-indene at the power plant in Senden could be explained by incomplete conversion of heavier hydrocarbons into smaller gaseous molecules. Lab-scale tests were conducted to clarify the catalytic activity of the normally used bed material, which is olivine. Steam reforming of $1 \mathrm{H}-$ indene is only possible in the presence of a catalyst, since no conversion was observed when feldspar was used. Fresh olivine did show higher catalytic activity; however, on average only $24 \%$ of $1 \mathrm{H}$-indene was converted. Analogous to experiments conducted in a previous work using other hydrocarbons, such as toluene and $\mathrm{C}_{2} \mathrm{H}_{4}$ [34], the calcium-rich bed particle coating of used olivine led to a significant increase in its catalytic activity. $1 \mathrm{H}$-indene conversion of more than $70 \%$ was achieved during these experiments. Pure $\mathrm{CaO}$ used as the benchmark showed conversion of almost $100 \%$. As a consequence, it can be stated that the bed material, once it is in

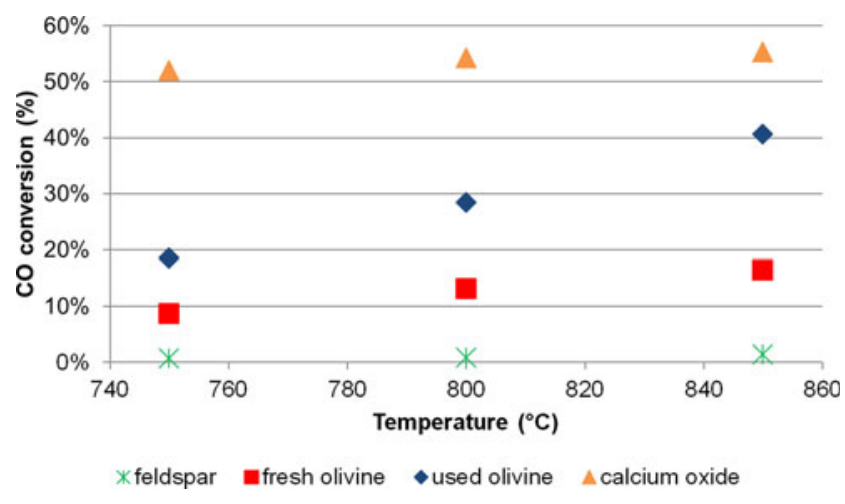

Fig. 8 Carbon monoxide conversion during the water-gas-shift reaction 


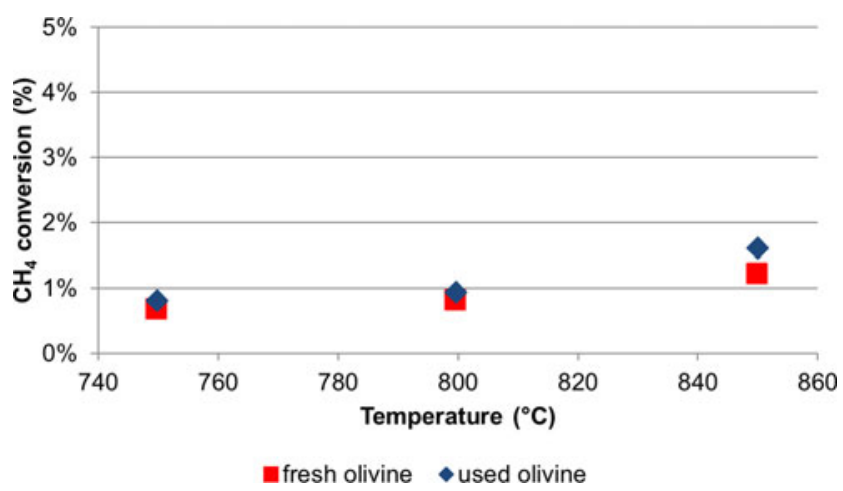

Fig. 9 Methane conversion during steam reforming

its active state with a calcium-rich coating, acts as an effective catalyst regarding the conversion of $1 \mathrm{H}$-indene. If this active state is reached, ensuring sufficient contact time between tars and catalyst due to uniform mixing of solid biomass and bed material in the fluidized bed leads to decreasing amounts of intermediate tar decomposition products. The higher catalytic activity of the material leads to increased amounts of $\mathrm{CO}_{2}$ compared to $\mathrm{CO}$. This is most likely a consequence of the water-gas-shift reaction, which occurs as a follow-up reaction.

Polymerization of $1 \mathrm{H}$-indene and as a result of the production of chrysene was observed during the lab-scale trials. The mechanism underpinning this recreation of five-membered to six-membered ring structures was investigated in detail by $\mathrm{Lu}$ and Mulholland [42]. It was found that the formation of chrysene is one possible outcome of aromatic hydrocarbon growth from $1 \mathrm{H}$-indene. The lab-scale experiments conducted in the present study showed that the higher the catalytic activity of the bed material, the lower the formation of chrysene. Since higher amounts of $1 \mathrm{H}$-indene are converted into smaller molecules, less $1 \mathrm{H}$-indene is available for the polymerization step. Therefore, the recreation of intermediate tar decomposition products into heavier poly-cyclic molecules can be prevented in the presence of a catalyst.

The water-gas-shift reaction, which occurred as a followup reaction in the steam reforming of $1 \mathrm{H}$-indene, was investigated in more depth. As shown in Fig. 8, this reaction also needs the presence of a catalyst, since feldspar did not lead to any conversion of $\mathrm{CO}$. Similar to the findings for $1 \mathrm{H}$-indene, used olivine showed increased catalytic activity compared to fresh olivine. Therefore, calcium-rich bed particle coatings also have a significant influence on the water-gas-shift reaction. Pure $\mathrm{CaO}$ showed the highest activity of the investigated materials and almost reached the equilibrium of the reaction, demonstrating the essential role of $\mathrm{Ca}$ in the bed particle coating. The findings discussed above strengthen the importance of sufficient contact time between coated (activated, used) bed particles and volatile matter from the biomass feedstock.

The typical product gas composition of the DFB gasifier shows the presence of 8-12\% methane, depending on the bed temperature [40]. Figure 9 shows that neither fresh nor used olivine possesses high enough catalytic activity for noteworthy conversion of methane. Methane is, therefore, the only hydrocarbon investigated so far that is stable enough to withstand significant catalytic conversion in the presence of bed materials coated with a calcium-rich layer. Due to the stability of the methane molecule, only specific catalysts reduce the activation energy enough to enable the steam reforming process (e.g., Ni catalysts). This is of relevance when using DFB gasification for the production of bio- $\mathrm{CH}_{4}$, where the presence of methane in the product gas is desired. Furthermore, it shows that there is not necessarily a causal correlation between the amount of methane and the amount of tar in the product gas, since tar is highly influenced by bed particle coatings in contrast to methane. Using methane as measurable tar indication compound during operation of an industrial power plant has therefore to be treated with caution until deeper understanding of reaction pathways is gained. In addition, a minor influence of the temperature was observed between 750 and $850^{\circ} \mathrm{C}$ in comparison to the water-gas-shift reaction, where the temperature had a significantly greater influence.

$\mathrm{CaO}$ showed the best performance of the bed materials tested; however, a high attrition rate hinders its use as a bed material.

The collective results of these and previous investigations $[33,35,36,40]$ provide insight into the influence of calciumrich bed particle coatings regarding the conversion of different hydrocarbons.

\section{Conclusion}

Based on these investigations, the following conclusions can be drawn:

1.The bed material has to be in its active state, which is achieved through the development of Ca-rich layers originating from interactions with biomass ash, to obtain satisfactory conversion of $1 \mathrm{H}$-indene. Sufficient contact time between the catalytically active bed material and tars must be ensured.

2.Steam reforming of $1 \mathrm{H}$-indene is linked to the water-gasshift reaction. As a result, part of the $\mathrm{CO}$ produced during steam reforming is further converted into $\mathrm{H}_{2}$ and $\mathrm{CO}_{2}$ in the presence of $\mathrm{H}_{2} \mathrm{O}$. Analogous to the findings for $1 \mathrm{H}$-indene, Ca-rich layers have a significant influence on the conversion of $\mathrm{CO}$ in the water-gas-shift reaction.

3.The increase of the catalytic activity of the bed material caused by the formation of Ca-rich layers does not affect the conversion of methane through steam reforming to a noteworthy extent. Due to the stability of the methane molecule, the increased activity is still too low to enable conversion under the investigated conditions.

In conclusion, understanding the influence of bed particle layers on the decomposition and conversion of hydrocarbons 
is essential for stable and reliable operation and to obtain a specific product gas composition.

Acknowledgments Open access funding provided by TU Wien (TUW). This study was carried out in the framework of the Bioenergy2020+ project C20016016. Bioenergy2020+ GmbH is funded within the Austrian COMET program, which is managed by the Austrian Research Promotion Agency (FFG) and promoted by the Federal Government of Austria as well as the Federal States of Burgenland, Niederösterreich, and Steiermark. We are grateful for the support of our project partners HGA Senden (Stadtwerke Ulm) and the Institute of Chemical Engineering at the Vienna University of Technology.

Open Access This article is distributed under the terms of the Creative Commons Attribution 4.0 International License (http:// creativecommons.org/licenses/by/4.0/), which permits unrestricted use, distribution, and reproduction in any medium, provided you give appropriate credit to the original author(s) and the source, provide a link to the Creative Commons license, and indicate if changes were made.

\section{References}

1. Kaltschmitt M, Hartmann H, Hofbauer H. Energie aus biomasse. Berlin, Heidelberg: Springer Berlin Heidelberg; 2001. doi:10.1007/ 978-3-662-07025-3.

2. Hofbauer H, Rauch R, Loeffler G, Kaiser S, Fercher E, Tremmel H. Six years experience with the FICFB-gasification process. Proc. 12th Eur. Conf. Technol. Exhib. Biomass Energy, Ind. Clim. Prot., Amsterdam, The Netherlands: 2002, p. 982-5.

3. Rehling B, Hofbauer H, Rauch R, Aichernig C (2011) BioSNGprocess simulation and comparison with first results from a 1-MW demonstration plant. Biomass Convers Biorefinery 1:111-119. doi: 10.1007/s13399-011-0013-3

4. Agerborg J, Lingehed E (2013) Integration of power-to-gas in gasendal and GoBiGas. Chalmers University of Technology, Master's Thesis

5. Rauch R, Hrbek J, Hofbauer H (2014) Biomass gasification for synthesis gas production and applications of the syngas. Wiley Interdiscip Rev Energy Environ 3:343-362. doi:10.1002/wene.97

6. Sauciuc A, Abosteif Z, Weber G, Potetz A, Rauch R, Hofbauer H, et al. (2011) Influence of pressure on the performance of biomass based Fischer-Tropsch synthesis. Vienna, Austria, Proc. Int. Conf. Polygeneration Strateg.

7. Fail S, Diaz N, Benedikt F, Kraussler M, Hinteregger J, Bosch K, et al. (2014) Wood gas processing to generate pure hydrogen suitable for PEM fuel cells. ACS Sustain Chem Eng 2:2690-2698. doi:10. $1021 / \mathrm{sc} 500436 \mathrm{~m}$

8. Benedikt F, Kraussler M, Konlechner D, Bosch K, Hackel M, Hofbauer $\mathrm{H}$. polygeneration at the biomass steam gasification plant oberwart - evaluation of process chains to produce hydrogen, electricity and heat. Proc. 23rd Eur. Biomass Conf. Exhib., Vienna, Austria: 2015, p. 1-4.

9. Chianese S, Loipersböck J, Malits M, Rauch R, Hofbauer H, Molino A, et al. (2015) Hydrogen from the high temperature water gas shift reaction with an industrial $\mathrm{Fe} / \mathrm{Cr}$ catalyst using biomass gasification tar rich synthesis gas. Fuel Process Technol 132:39-48. doi:10.1016/j.fuproc.2014.12.034

10. Weber G, Rauch R, Hofbauer H (2014) Influence of ethylene on the formation of mixed alcohols over a MoS2 catalyst using biomassderived synthesis gas. Biomass Convers Biorefinery 07:85-94. doi: 10.1007/s13399-014-0140-8

11. Schmid JC, Pfeifer C, Kitzler H, Pröll T, Hofbauer H. A new dual fluidized bed gasifier design for improved in situ conversion of hydrocarbons. Proc. Int. Conf. Polygeneration Strateg., Vienna, Austria: 2011, p. 1-10.

12. Schmid JC, Pröll T, Pfeifer C, Hofbauer H. Improvement of gassolid interaction in dual circulating fluidized bed systems. Proc. 9th Eur. Conf. Ind. Furn. Boil., Estoril, Portugal: 2011, p. 1-13.

13. Pfeifer C, Schmid JC, Pröll T, Hofbauer H. Next generation biomass gasifier. Proc. 19th Eur. Biomass Conf. Exhib., Berlin, Germany: 2011, p. 1-7.

14. Basu P (2010) Biomass gasification and pyrolysis. Elsevier Inc., Oxford. doi:10.1016/B978-0-12-374988-8.00005-2

15. Devi L, Ptasinski KJ, Janssen FJJG (2005) Decomposition of naphthalene as a biomass tar over pretreated olivine: effect of gas composition, kinetic approach, and reaction scheme. Ind Eng Chem Res 44:9096-9104. doi:10.1021/ie050801g

16. Devi L, Ptasinski KJ, Janssen FJJG, Van Paasen SVB, Bergman PCA, Kiel JHA (2005) Catalytic decomposition of biomass tars: use of dolomite and untreated olivine. Renew Energy 30:565-587. doi:10.1016/j.renene.2004.07.014

17. Nair SA, Yan K, Pemen AJM, van Heesch EJM, Ptasinski KJ, Drinkenburg AAH (2004) Tar removal from biomass-derived fuel gas by pulsed corona discharges. A chemical kinetic study. Ind Eng Chem Res 43:1649-1658. doi:10.1021/ie034066p

18. Coll R, Salvadó J, Farriol X, Montané D (2001) Steam reforming model compounds of biomass gasification tars: conversion at different operating conditions and tendency towards coke formation. Fuel Process Technol 74:19-31. doi:10.1016/S0378-3820(01) 00214-4

19. Zamboni I, Courson C, Niznansky D, Kiennemann A (2014) Simultaneous catalytic $\mathrm{H} 2$ production and $\mathrm{CO} 2$ capture in steam reforming of toluene as tar model compound from biomass gasification. Appl Catal B Environ 145:63-72. doi:10.1016/j.apcatb. 2013.02.046

20. Zhao B, Zhang X, Chen L, Qu R, Meng G, Yi X, et al. (2010) Steam reforming of toluene as model compound of biomass pyrolysis tar for hydrogen. Biomass Bioenergy 34:140-144. doi:10.1016/j. biombioe.2009.10.011

21. Kong M, Yang Q, Fei J, Zheng X (2012) Experimental study of Ni/ $\mathrm{MgO}$ catalyst in carbon dioxide reforming of toluene, a model compound of tar from biomass gasification. Int J Hydrog Energy 37:13355-13364. doi:10.1016/j.ijhydene.2012.06.108

22. Biagini E, Barontini F, Tognotti L (2006) Devolatilization of biomass fuels and biomass components studied by TG/FTIR technique. Ind Eng Chem Res 45:4486-4493. doi:10.1021/ie0514049

23. Swierczynski D, Courson C, Kiennemann A (2008) Study of steam reforming of toluene used as model compound of tar produced by biomass gasification. Chem Eng Process Process Intensif 47:508 513. doi:10.1016/j.cep.2007.01.012

24. Kuba M, Kirnbauer F, Hofbauer H (2015) The role of $1 \mathrm{H}$-indene in product gas of biomass gasification. Shanghai, China, Contrib. to Int. Bioenergy Exhib. Bioenergy Conf.

25. Kirnbauer F, Koch M, Koch R, Aichernig C, Hofbauer H (2013) Behavior of inorganic matter in a dual fluidized steam gasification plant. Energy Fuel 27:3316-3331. doi:10.1021/ef400598h

26. Öhman M, Pommer L, Nordin A (2005) Bed agglomeration characteristics and mechanisms during gasification and combustion of biomass fuels. Energy and Fuels 19:1742-1748. doi:10.1021/ef040093w

27. Kirnbauer F, Hofbauer H (2011) Investigations on bed material changes in a dual fluidized bed steam gasification plant in Güssing, Austria. Energy and Fuels 25:3793-3798. doi:10.1021/ ef200746c

28. Tranvik AC, Öhman M, Sanati M (2007) Bed material deposition in cyclones of wood fuel fired circulating fluidized beds (CFBs). Energy and Fuels 21:104-109. doi:10.1021/ef060175f

29. Brus E, Öhman M, Nordin A (2005) Mechanisms of bed agglomeration during fluidized-bed combustion of biomass fuels. Energy and Fuels 19:825-832. doi:10.1021/ef0400868 
30. Kuba M, He H, Kirnbauer F, Boström D, Öhman M, Hofbauer H (2015) Deposit build-up and ash behavior in dual fluid bed steam gasification of logging residues in an industrial power plant. Fuel Process Technol 139:33-41. doi:10.1016/j.fuproc.2015.08.017

31. Scala F, Chirone R (2008) An SEM/EDX study of bed agglomerates formed during fluidized bed combustion of three biomass fuels. Biomass Bioenergy 32:252-266. doi:10.1016/j. biombioe.2007.09.009

32. Fryda LE, Panopoulos KD, Kakaras E (2008) Agglomeration in fluidised bed gasification of biomass. Powder Technol 181:307320. doi:10.1016/j.powtec.2007.05.022

33. Kirnbauer F, Wilk V, Kitzler H, Kern S, Hofbauer H (2012) The positive effects of bed material coating on tar reduction in a dual fluidized bed gasifier. Fuel 95:553-562. doi:10.1016/j.fuel.2011. 10.066

34. Kuba M, Havlik F, Kirnbauer F, Hofbauer H (2015) Influence of bed material coatings on the water-gas-shift reaction and steam reforming of toluene as tar model compound of biomass gasification. Biomass Bioenergy. doi:10.1016/j.biombioe.2015.11.029

35. Kuba M, Havlik F, Kirnbauer F, H. Hofbauer. Investigations on the catalytic activity of bed material coating regarding the water-gasshift reaction and steam reforming of model compounds for lighter and heavier hydrocarbons. Proc. 23rd Eur. Biomass Conf. Exhib., Vienna, 2015, p. 1-4.

36. Kern S, Pfeifer C, Hofbauer H (2013) Reactivity tests of the watergas shift reaction on fresh and used fluidized bed materials from industrial DFB biomass gasifiers. Biomass Bioenergy 55:227-233. doi:10.1016/j.biombioe.2013.02.001

37. Devi L, Craje M, Thüne P, Ptasinski KJ, Janssen FJJG (2005) Olivine as tar removal catalyst for biomass gasifiers: catalyst characterization. Appl Catal A Gen 294:68-79. doi:10.1016/j.apcata. 2005.07.044

38. Christodoulou C, Grimekis D, Panopoulos KD, Pachatouridou EP, Iliopoulou EF, Kakaras E (2014) Comparing calcined and untreated olivine as bed materials for tar reduction in fluidized bed gasification. Fuel Process Technol 124:275-285. doi:10.1016/j. fuproc.2014.03.012

39. Kirnbauer F, Hofbauer H (2013) The mechanism of bed material coating in dual fluidized bed biomass steam gasification plants and its impact on plant optimization. Powder Technol 245:94-104. doi: 10.1016/j.powtec.2013.04.022

40. Kirnbauer F, Wilk V, Hofbauer H (2013) Performance improvement of dual fluidized bed gasifiers by temperature reduction: the behavior of tar species in the product gas. Fuel 108:534-542. doi:10. 1016/j.fuel.2012.11.065

41. van de Kamp W, de Wild P, Zielke U, Suomalainen M, Knoef H, Good J, et al. Tar measurement standard for sampling and analysis of tars and particles in biomass gasification product gas. Proc. 14th Eur. Biomass Conf. Exhib., Paris, France: 2005, p. 791-4.

42. Lu M, Mulholland JA (2001) Aromatic hydrocarbon growth from indene. Chemosphere 42:625-633. doi:10.1016/S0045-6535(00) 00236-8 